\title{
Correlation between SATB1 and Bcl-2 expression in human glioblastoma multiforme
}

\author{
SHENG-HUA CHU ${ }^{1}$, YAN-BIN MA ${ }^{1}$, DONG-FU FENG ${ }^{1}$, \\ ZHI-QIANG LI ${ }^{2}$ and PU-CHA JIANG ${ }^{2}$ \\ ${ }^{1}$ Department of Neurosurgery, No. 3 People's Hospital Affiliated to Shanghai Jiao Tong University School of Medicine, \\ Shanghai 201900; ${ }^{2}$ Department of Neurosurgery, Zhongnan Hospital of Wuhan University, Wuhan 430071, P.R. China
}

Received July 9, 2012; Accepted October 2, 2012

DOI: $10.3892 / \mathrm{mmr} .2012 .1131$

\begin{abstract}
Special AT-rich sequence-binding protein-1 (SATB1) has been reported to be overexpressed in numerous human tumors. The aim of the present study was to determine the correlation and clinical significance between the expression of SATB1 and B-cell lymphoma 2 (Bcl-2) in human glioblastoma multiforme (GBM). Samples from 70 patients with GBMs were analyzed and 10 normal brain tissues were used as the control group. In situ hybridization was used to detect SATB1 mRNA expression and immunohistochemistry was used to detect Bcl-2 and proliferating cell nuclear antigen (PCNA) protein expression. Apoptosis was detected with flow cytometry. The SATB1 mRNA and Bcl-2 protein levels were found to be significantly higher in GBM tissues than in normal brain and their levels were associated with patient survival, but not associated with patient gender, age and tumor size and site. A positive correlation was observed between SATB1 mRNA and Bcl-2 protein and between SATB1 mRNA and PCNA. A negative correlation was observed between SATB1 mRNA and apoptosis and between $\mathrm{Bcl}-2$ and apoptosis. A positive correlation existed between Bcl-2 and PCNA. Patients with GBM identified as SATB1 mRNA (+) and Bcl-2 (+) were associated with a poor prognosis. Therefore, assessment of SATB1 and $\mathrm{Bcl}-2$ co-expression may provide important information for the diagnosis, therapy and prognosis of GBM.
\end{abstract}

\section{Introduction}

Glioblastoma multiforme (GBM) is the most common and lethal glial tumor of the adult brain, accounting for approximately $50 \%$ of all gliomas. GBM is characterized by an

Correspondence to: Dr Sheng-Hua Chu, Department of Neurosurgery, No. 3 People's Hospital Affiliated to Shanghai Jiao Tong University School of Medicine, 280 Mohe Road, Baoshan, Shanghai 201900, P.R. China

E-mail: shenghuachu@126.com

Key words: glioblastoma multiforme, SATB1, Bcl-2, expression, apoptosis aggressive growth pattern, a marked degree of invasiveness and extremely poor prognosis. Even after multimodal treatment approaches, the median survival of patients with GBM following the primary diagnosis remains poor. An improved understanding of the genetic background and molecular pathogenic processes involved in the tumorigenesis of GBM is therefore critical for the development of rational, targeted therapies (1-5).

Special AT-rich sequence-binding protein 1 (SATB1) is a cell type-specific nuclear matrix attachment regionbinding protein that links specific DNA elements to its cage-like network (6) and is predominantly expressed in thymocytes (7). SATB1 facilitates the formation of an open chromatin structure and is involved in the regulation of hundreds of genes. SATB1 has recently received considerable attention from the cancer research field due to high expression in various malignant tumor tissues (8-10), indicative of a tumor growth promoter. To explore the roles of SATB1 in the clinical progression of GBM, the present study examined the correlation between expression of SATB1 and Bcl-2 in GBM and tumor apoptosis, in order to shed new light on GBM therapy.

\section{Materials and methods}

Patients and tissue samples. Seventy cases of surgically resected GBMs were collected from the 2007-2010 pathology files of the Third People's Hospital Affiliated to Shanghai Jiao Tong University School of Medicine and Zhongnan Hospital of Wuhan University. Approval was obtained from the Ethics committee of the Third People's Hospital Affiliated to Shanghai Jiao Tong University School of Medicine and Zhongnan Hospital of Wuhan University. Specimens were handled and made anonymous according to ethical and legal standards. Written informed consent was obtained from all patients. There were 40 males and 30 females with a mean age of 46 years (range, 29-68). None of the patients had received chemical therapy or radiotherapy prior to surgery. Control brain tissues were obtained from 10 individuals, who had died in traffic accidents exhibiting no prior pathologically detectable condition. Based on the results of hematoxylineosin staining, histopathological diagnosis was performed by various neuropathologists. 


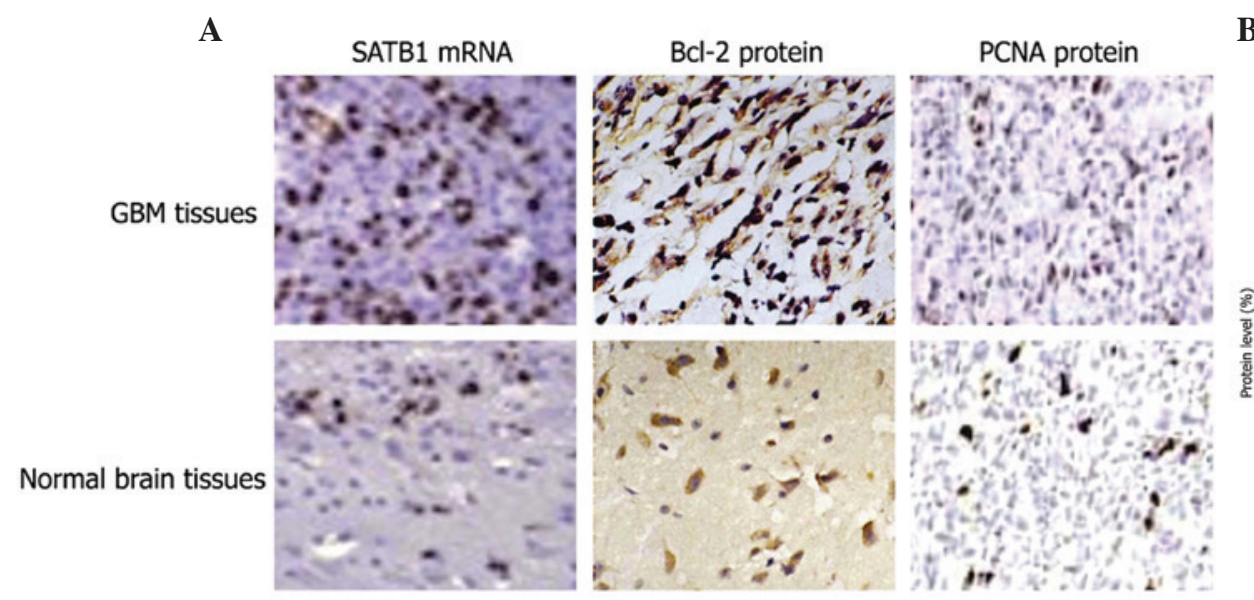

$\mathbf{B}$

Figure 1. SATB1 mRNA, Bcl-2 and PCNA protein expression in tissues. (A) Representative images of SATB1 mRNA, Bcl-2 and PCNA protein expression in GBM and normal brain tissues. (B) Quantitative analysis of SATB1 mRNA, Bcl-2 and PCNA protein expression in GBM tissues and the normal brain tissues. SATB1, special AT-rich sequence-binding protein-1; Bcl-2, B-cell lymphoma-2; PCNA, proliferating cell nuclear antigen; GBM, glioblastoma multiforme.

In situ hybridization. Frozen sections were immersed in a solution of $30 \%$ hydrogen dioxide and methanol for 30 min following brief warming at room temperature, then incubated at $37^{\circ} \mathrm{C}$ with pepsin diluted by $3 \%$ citric acid. Sections were postfixed for $10 \mathrm{~min}$ in $1 \%$ paraformaldehyde and were incubated at $38-42^{\circ} \mathrm{C}$ with DIG-labeled antisense cRNA probes overnight in a humidified chamber. Following multiple washes in 4X SSC at room temperature, the slides were incubated at $37^{\circ} \mathrm{C}$ in a blocking reagent for $30 \mathrm{~min}$, a biotinylated anti-digoxin antibody for $60 \mathrm{~min}$, SABC for $20 \mathrm{~min}$ and the biotinylated peroxydase for $20 \mathrm{~min}$, at $37^{\circ} \mathrm{C}$, followed by staining with DAB (Sigma, St. Louis, MO, USA). Sections were then covered with glycerol-gelatin and coverslips for microscopic examination $(11,12)$. The SATB1 probe (sequence: 5'-TCTTTAATTTCTAATATATTTAGAA-3') was synthesized and labeled with biotin at the $5^{\prime}$ end by Sangon Bioengineering Technology and Services Co., Ltd. (Shanghai, China). The probe was replaced with the dilution solution in control samples.

Immunohistochemical analysis. Antigen retrieval was performed in boiling citrate buffer for $15 \mathrm{~min}$. Peroxide blocking was performed with $0.3 \%$ peroxide in absolute methanol. The slides were then incubated with anti-Bcl-2 polyclonal antibody (diluted 1:300; Sigma) or mouse anti-PCNA monoclonal antibody (diluted 1:100; Santa Cruz Biotechnology, Inc., Santa Cruz, CA, USA) at $4^{\circ} \mathrm{C}$ overnight and washed twice with phosphate-buffered saline prior to incubation with a secondary antibody (Santa Cruz Biotechnology, Inc.) at room temperature for $30 \mathrm{~min}$. After washing, the sections were incubated with immunoglobulins conjugated with horseradish peroxidase. The reaction was then developed with 3,3'-diaminobenzidine substrate $(2,13)$. Tissue sections were counterstained with hematoxylin or methyl green.

Quantification of SATB1 $\mathrm{mRNA}, \mathrm{Bcl}-2$ and PCNA protein. The nucleoli of SATB1-positive cells, cytoplasm of Bcl-2-positive cells (14) and nuclei of PCNA-positive cells were stained brown-yellow. Images of the sections were obtained (magnification, x100) using the HPIAS-1000 High Resolution
Color Pathological Image Analysis System (Tongji Medical College Qianping Imaging Engineering Co., Ltd., Shanghai, China) (15). Specimens with a positive cell ratio $<30 \%$ were defined as negative.

Measurement of apoptosis by flow cytometry. Tissues collected in RPMI-1640 medium supplemented with 10\% fetal bovine serum were processed routinely to generate single-cell suspensions $(16,17)$. Suspensions were then fixed in $70 \%$ cold ethanol, treated with $10 \mathrm{~g} / \mathrm{l}$ RNase and suspended and stained with $10 \mathrm{~g} / 1$ propidium iodine (PI). After washing with PBS, the cells were stained directly with PI at a final concentration of $10 \mu \mathrm{g} / \mathrm{ml}$ and $2 \%$ Annexin-V Flous (Roche, Basel, Swizerland) in incubation buffer for $10 \mathrm{~min}$. The cells were collected by FACSCalibur (BD Pharmingen, San Diego, CA, USA) following instrument set-up with controls (non-treated, stained cells) and two washes in PBS. In this experiment, cells with early apoptotic signals (stained with Annexin V) and cells with late death signals (stained with PI) were quantified and apoptotic cells were analyzed using the CellQuest software $(18,19)$. Each assay was performed in triplicate.

Statistical analysis. Quantitative values were expressed as the mean \pm SD. Statistical analysis was performed using the Pearson method and a Student's or Chi-squared test using SPSS 12.0 (for Windows; SPSS, Chicago, IL, USA). P<0.05 was considered to indicate a statistically significant difference.

\section{Results}

SATB1 expression by in situ hybridization. The majority of brown-positive staining for in situ hybridization of SATB1 mRNA was homogeneously distributed within the nucleolus (Fig. 1A). SATB1 mRNA expression levels were found to be significantly higher in GBM than in the normal brain tissues (Fig. 1B; P<0.01).

Immunohistochemical analysis of Bcl-2 and PCNA protein expression. Immunohistochemical staining revealed $\mathrm{Bcl}-2$ protein expression in both the cytoplasm and cell membrane 
Table I. Correlation of SATB1 and Bcl-2 expression with clinical variables of GBM.

\begin{tabular}{|c|c|c|c|c|c|}
\hline Variables & $\mathrm{n}$ & SATB1 $(\%)$ & P-value & $\mathrm{Bcl}-2(\%)$ & P-value \\
\hline \multicolumn{6}{|l|}{ Gender } \\
\hline Male & 40 & $43.63 \pm 7.23$ & 0.332 & \multirow[t]{2}{*}{$33.24 \pm 5.75$} & \multirow[t]{2}{*}{0.558} \\
\hline Female & 30 & $41.83 \pm 8.14$ & $32.35 \pm 6.88$ & & \\
\hline \multicolumn{6}{|l|}{ Age (years) } \\
\hline$\geq 46$ & 34 & $41.92 \pm 6.96$ & 0.302 & \multirow[t]{2}{*}{$32.23 \pm 6.21$} & \multirow[t]{2}{*}{0.388} \\
\hline$<46$ & 36 & $43.74 \pm 7.65$ & $33.45 \pm 5.54$ & & \\
\hline \multicolumn{6}{|c|}{ Tumor size $\left(\mathrm{cm}^{3}\right)$} \\
\hline$\geq 4$ & 41 & $44.12 \pm 7.45$ & 0.109 & \multirow[t]{2}{*}{$34.02 \pm 7.12$} & \multirow[t]{2}{*}{0.103} \\
\hline$<4$ & 29 & $41.07 \pm 8.12$ & $31.21 \pm 6.85$ & & \\
\hline \multicolumn{6}{|l|}{ Tumor site } \\
\hline Supratentorial & 45 & $42.79 \pm 7.52$ & 0.919 & \multirow[t]{2}{*}{$32.80 \pm 5.23$} & \multirow[t]{2}{*}{0.906} \\
\hline Infratentorial & 25 & $42.98 \pm 7.44$ & $32.96 \pm 5.78$ & & \\
\hline \multicolumn{6}{|c|}{ Survival rate (years) } \\
\hline$\geq 1$ & 29 & $37.18 \pm 7.68$ & 0.000 & \multirow[t]{2}{*}{$28.34 \pm 6.23$} & \multirow[t]{2}{*}{0.000} \\
\hline$<1$ & 41 & $46.87 \pm 8.92$ & $36.05 \pm 7.48$ & & \\
\hline
\end{tabular}

SATB1, special AT-rich sequence-binding protein-1; Bcl-2, B-cell lymphoma-2; GBM, glioblastoma multiforme.
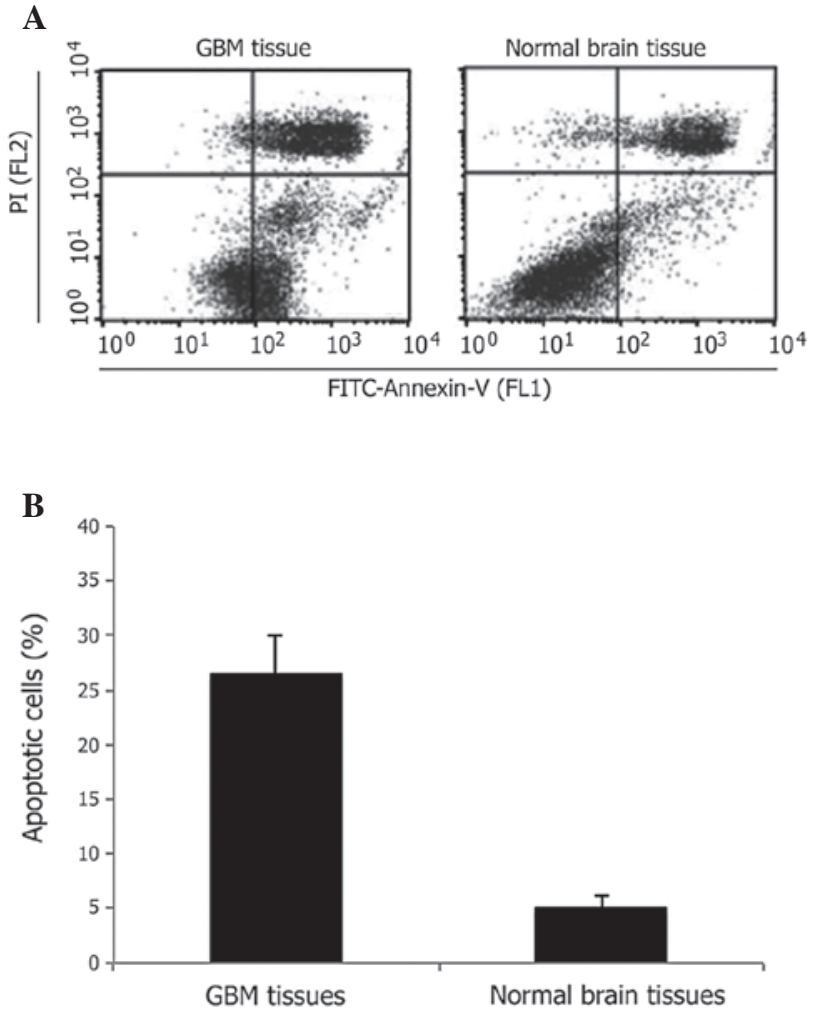

Figure 2. FACS analysis of Annexin-V staining of cells in GBM tissues and the normal brain tissues. (A) Representative FACS scatter plots of cells indicating apoptotic cell death. (B) Percentages of apoptotic cells in tissues. GBM, glioblastoma multiforme.

(Fig. 1A). PCNA protein expression was primarily detected in the nucleolus (Fig. 1A). Expression of $\mathrm{Bcl}-2$ and PCNA protein was noted at significantly higher levels in GBM tissues than in normal brain tissues (Fig. $1 \mathrm{~B}, \mathrm{P}<0.01$ ).
Measurement of apoptosis by flow cytometry. To quantify apoptotic cell death in tissues, $\sim 1 \times 10^{6}$ cells were double stained with Annexin V-FITC and PI at various times post-transfection. Apoptotic cell death was detected in GBM and normal brain tissues (Fig. 2A). FACS analysis identified a significantly higher number of apoptotic cells in GBM tissues than normal brain tissues (Fig. 2B; $\mathrm{P}<0.01$ ).

Correlation between SATB1 and Bcl-2 expression and clinical characteristics of GBM. SATB1 mRNA and Bcl-2 protein expression levels were associated with the survival rate of patients $(\mathrm{P}<0.01)$, but were not associated with patient gender, age and tumor size and site (Table I).

Correlation between SATB1 and Bcl-2 expression, PCNA and apoptosis. Statistical analysis revealed a positive correlation between SATB1 mRNA and Bcl-2 protein levels $(\mathrm{P}<0.05)$ and between SATB1 mRNA and PCNA protein levels $(\mathrm{P}<0.01)$. A negative correlation was identified between SATB1 and apoptosis $(\mathrm{P}<0.01)$ and between $\mathrm{Bcl}-2$ and apoptosis $(\mathrm{P}<0.01)$. However, a positive correlation was observed between Bcl-2 and PCNA $(\mathrm{P}<0.01)$, whereas a negative correlation was found between PCNA and apoptosis $(\mathrm{P}<0.01$; Table II).

Co-expression of SATB1 and Bcl-2. SATB1-positive cases (+) were divided into two groups consisting of a survival rate $<1$ and $\geq 1$ year. Differences between the groups were evaluated according to the Bcl-2 protein expression and identified as $\chi^{2}=20.95(\mathrm{P}<0.001 ;$ Table III $)$.

\section{Discussion}

SATB1 is a tissue-specific nuclear matrix-attachment DNA-binding protein, which is located on chromosome 3 p23. 
Table II. Correlation between SATB1, Bcl-2, PCNA expression and apoptosis in GBM.

\begin{tabular}{lcccc}
\hline Variables & SATB1 & Bcl-2 & PCNA & Apoptosis \\
\hline SATB1 & - & $0.542^{\mathrm{a}}$ & $0.615^{\mathrm{b}}$ & $-0.534^{\mathrm{a}}$ \\
Bcl-2 & $0.542^{\mathrm{a}}$ & - & $-0.536^{\mathrm{a}}$ & $-0.586^{\mathrm{b}}$ \\
PCNA & $0.615^{\mathrm{b}}$ & $-0.536^{\mathrm{a}}$ & - & $-0.532^{\mathrm{a}}$ \\
Apoptosis & $-0.534^{\mathrm{a}}$ & $-0.586^{\mathrm{b}}$ & $-0.532^{\mathrm{a}}$ & - \\
\hline
\end{tabular}

${ }^{\mathrm{a}} \mathrm{P}<0.05,{ }^{\mathrm{b}} \mathrm{P}<0.01$. Values indicate the correlation coefficient $\mathrm{r}$. SATB1, special AT-rich sequence-binding protein-1; Bcl-2, B-cell lymphoma-2; PCNA, proliferating cell nuclear antigen; GBM, glioblastoma multiforme.

Table III. Correlation between SATB1, Bcl-2 and survival time.

\begin{tabular}{lcc}
\hline & \multicolumn{2}{c}{ Survival time } \\
\cline { 2 - 3 } Variables & $\geq 1$ year & $<1$ year \\
\hline $\mathrm{S}^{+} \mathrm{B}^{+}$ & 6 & 29 \\
$\mathrm{~S}^{+} \mathrm{B}^{-}$ & 16 & 4 \\
\hline
\end{tabular}

SATB1, special AT-rich sequence-binding protein-1; Bcl-2, B-cell lymphoma 2; S, SATB1; B, Bcl-2.

SATB1 has previously attracted considerable attention in the cancer research field due to its high expression in tumor tissues of a variety of malignancies (8-10), indicative of a crucial role in the promotion of tumor growth and prediction of tumor prognosis. It was previously demonstrated that overexpression of SATB1 correlates with the metastatic potential of human gastric cancer and may be suitable for use as a novel independent prognostic marker for the prediction of gastric cancer outcome (20). Bcl-2 is expressed in various tissues under normal conditions, with the physiological function of the modulation of apoptotis and cell number balance (21). Two important factors of cell number control are rate of apoptosis and proliferation $(22,23)$. Overexpression of SATB1 and/or $\mathrm{Bcl}-2$ disturbs this balance and contributes to the proliferation and anti-apoptotic functions of the abnormal cell.

Results of the present study have demonstrated that expression of SATB1 mRNA and Bcl-2 protein is significantly higher in GBM tissues than in the normal brain tissues. With regard to clinical features, expression of SATB1 and Bcl-2 was correlated with patient survival, but was not associated with patient gender, age and tumor size and site. Overexpression of SATB1 mRNA and Bcl-2 protein was higher in the survival $<1$ year group than the $\geq 1$ year and a significant positive correlation between SATB1 and Bcl-2 was observed. We analyzed the correlation between SATB1, Bcl-2, PCNA and apoptosis. A positive correlation between SATB1 mRNA and PCNA was observed. A negative correlation between SATB1 mRNA and apoptosis and between $\mathrm{Bcl}-2$ and apoptosis was observed and a positive correlation was found between Bcl-2 and PCNA.
These data suggest that SATB1 functions in the promotion of cell proliferation and inhibition of apoptosis. Function of $\mathrm{Bcl}-2$ is restricted to inhibiting apoptosis. Consistent with this hypothesis, cases positive for SATB1 and Bcl-2 were associated with poor prognosis, thus, assessment of SATB1 and $\mathrm{Bcl}-2$ co-expression may provide useful information for the diagnosis, therapy and prognosis of GBM.

\section{Acknowledgements}

This study was supported by grants from the Innovation Program of Shanghai Municipal Education Commission (12YZ046) and the New One Hundred Person Project of Shanghai Jiao Tong University of School of Medicine (10XBR01).

\section{References}

1. Wen PY and Kesari S: Malignant gliomas in adults. N Engl J Med 359: 492-507, 2008.

2. Chu SH, Ma YB, Feng DF, Zhang H, Zhu ZA, Li ZQ and Jiang PC: Correlation of low SLC22A18 expression with poor prognosis in patients with glioma. J Clin Neurosci 19: 95-98, 2012.

3. Chu SH, Feng DF, Ma YB, Zhang H, Zhu ZA, Li ZQ and Jiang PC: Promoter methylation and downregulation of SLC22A18 are associated with the development and progression of human glioma. J Transl Med 9: 156, 2011.

4. Chu SH, Ma YB, Feng DF, Zhang H, Qiu JH and Zhu ZA: Effect of 5-Aza-2'-deoxycytidine on SLC22A18 in glioma U251 cells. Mol Med Rep 5: 138-141, 2012.

5. Yang FY, Teng MC, Lu M, Liang HF, Lee YR, Yen CC, Liang ML and Wong TT: Treating glioblastoma multiforme with selective high-dose liposomal doxorubicin chemotherapy induced by repeated focused ultrasound. Int J Nanomedicine 7: 965-974, 2012.

6 . Kouzarides T: Histone acetylases and deacetylases in cell proliferation. Curr Opin Genet Dev 9: 40-48, 1999.

7. Dickinson LA, Joh T, Kohwi Y and Kohwi-Shigematsu T: A tissue-specific MAR/SAR DNA-binding protein with unusual binding site recognition. Cell 70: 631-645, 1992.

8. Han HJ, Russo J, Kohwi Y and Kohwi-Shigematsu T: SATB1 reprogrammes gene expression to promote breast tumour growth and metastasis. Nature 452: 187-193, 2008.

9. Meng WJ, Yan H, Zhou B, Zhang W, Kong XH, Wang R, Zhan L, Li Y, Zhou ZG and Sun XF: Correlation of SATB1 overexpression with the progression of human rectal cancer. Int J Colorectal Dis 27: $143-150,2012$.

10. Chen H, Takahara M, Oba J, Xie L, Chiba T, Takeuchi S, Tu Y, Nakahara T, Uchi H, Moroi Y and Furue M: Clinicopathologic and prognostic significance of SATB1 in cutaneous malignant melanoma. J Dermatol Sci 64: 39-44, 2011.

11. Liu M, Xiao GG, Rong P, Zhang Z, Dong J, Zhao H, Li H, Li Y, Pan J, Liu H, Wang W, Zha Q and Ju D: Therapeutic effects of Radix Dipsaci, Pyrola Herb and Cynomorium Songaricum on bone metabolism of ovariectomized rats. BMC Complement Altern Med 12: 67, 2012.

12. Chu SH, Yuan XH, Jiang PC, Li ZQ, Zhang J, Wen ZH, Zhao SY, Chen XJ and Cao CJ: The expression of hepatocyte growth factor and its receptor in brain astrocytomas. Zhonghua Yi Xue Za Zhi 85: 835-838, 2005 (In Chinese).

13. Chu SH, Feng DF, Ma YB, Zhang H, Zhu ZA, Li ZQ and Zhang ZH: Expression of HGF and VEGF in the cerebral tissue of adult rats with chronic hydrocephalus after subarachnoid hemorrhage. Mol Med Rep 4: 785-791, 2011.

14. Chu SH, Ma YB, Feng DF, Zhang H, Qiu JH and Zhu ZA: Elevated expression of solute carrier family 22 member 18 increases the sensitivity of U251 glioma cells to BCNU. Oncol Lett 2: 1139-1142, 2011.

15. Zhang H, Liu L, Huang G, Zhou L, Wu W, Zhang T and Huang H: Protective effect of electroacupuncture at the Neiguan point in a rabbit model of myocardial ischemia-reperfusion injury. Can $\mathrm{J}$ Cardiol 25: 359-363, 2009.

16. Demurtas A, Aliberti S, Bonello L, Di Celle PF, Cavaliere C, Barreca A, Novero D and Stacchini A: Usefulness of multiparametric flow cytometry in detecting composite lymphoma: study of 17 cases in a 12-year period. Am J Clin Pathol 135: 541-555, 2011. 
17. Wang E, Hutchinson CB, Huang Q, Lu CM, Crow J, Wang FF, Sebastian S, Rehder C, Lagoo A, Horwitz M, Rizzieri D, Yu J, Goodman B, Datto M and Buckley P: Donor cell-derived leukemias/myelodysplastic neoplasms in allogeneic hematopoietic stem cell transplant recipients: a clinicopathologic study of 10 cases and a comprehensive review of the literature. Am J Clin Pathol 135: 525-540, 2011.

18. Chu SH, Feng DF, Zhang H, Chen ET, Duan ZX, Li XY, Li J, Ma YB, Zhu ZA and Qiu JH: c-Met-targeted RNA interference inhibits growth and metastasis of glioma U251 cells in vitro. J Neurooncol 93: 183-189, 2009.

19. Chu S, Yuan X, Li Z, Jiang P and Zhang J: C-Met antisense oligodeoxynucleotide inhibits growth of glioma cells. Surg Neurol 65: 533-538, 2006.
20. Lu X, Cheng C, Zhu S, Yang Y, Zheng L, Wang G, Shu X, Wu K, Liu K and Tong Q: SATB1 is an independent prognostic marker for gastric cancer in a Chinese population. Oncol Rep 24: 981-987, 2010.

21. Wensveen FM, Alves NL, Derks IA, Reedquist KA and Eldering E: Apoptosis induced by overall metabolic stress converges on the Bcl-2 family proteins Noxa and Mcl-1. Apoptosis 16: 708-721, 2011.

22. Zhang MS, Hu AH, Qiu H, Xiong HH and Chen Y: The correlation between IGF-II and Bcl-2 expression in colorectal adenocarcinoma. Med Oncol 29: 928-932, 2012.

23. An YL, Nie F, Wang ZY and Zhang DS: Preparation and characterization of realgar nanoparticles and their inhibitory effect on rat glioma cells. Int J Nanomedicine 6: 3187-3194, 2011. 